Celestinesca 32 (2008): 151-163 https://doi.org/10.7203/Celestinesca.32.20112

\title{
Algunas consideraciones sobre la criada Lucrecia
}

\author{
Luis González Fernández \\ Université de Toulouse \\ FRAMESPA-UMR $5136 \mathrm{du}$ CNRS
}

Para mi maestro Alan Deyermond

En el elenco de sabrosos personajes que ofrece la Tragicomedia de Calisto y Melibea, la a veces casi transparente criada de Melibea, Lucrecia, tiene su momento de protagonismo un poco antes del final de la obra cuando, encendida de amor, se abalanza sobre Calisto y lo colma de atenciones y en absoluto castos abrazos. Este acontecimiento, que algunos críticos han intentado explicar como consecuencia de los efectos afrodisiacos de las canciones de amor cantadas por la criada momentos antes de la aparición del galán, sorprende no sólo al lector de la Tragicomedia, sino a la propia Melibea que no puede sino reprehender las desenfrenadas acciones de su criada ${ }^{1}$.

Los escasos pero admirables estudios referidos a la criada Lucrecia han logrado definir su papel con atino aunque, como casi siempre sucede con los personajes de esta obra, para cualquier afirmación existe una opinión contraria. Tras las encomiásticas páginas que le dedicó en su día María Rosa Lida de Malkiel, para quien Lucrecia es «La única honesta [de las tres mozas]», además de ser «de juicio prudente [...] mucho más honesta y más sesuda que la señora, a quien sirve con rara fidelidad» (1962: 643), Katherine Eaton y Rafael Beltrán, por citar sólo los estudios recientes más destacados, han aportado importantes matices para mejor explicar a este personaje secundario. Eaton se queja con razón del hecho de que: «Critical articles on Fernando de Rojas' La Celestina tend to ignore or gloss over the character of Melibea's maidservant Lucrecia» (Eaton, 1973: 213).

1.- Lida de Malkiel (1962: 645, n. 28) relega a una nota de pie de página un interesante comentario al que espero al menos responder en parte: "Desconcierta al lector de hoy la acotación descriptiva a cargo de Melibea». 
Rafael Beltrán (1997: 15-41), en su traducción y ampliación recientes de un artículo que vio la luz hace unos años, lamenta el hecho de que "ni las notas esenciales de $M^{a}$ Rosa Lida, ni el buen trabajo de Katherine Eaton dedicado al personaje [...] han tenido continuaciones [...], ni apenas matizaciones» (1997: 16, n. 2). Nos habla Beltrán del papel de secundaria que le toca desempeñar a Lucrecia, y lo estudia con acierto, trayendo a colación las ocasiones más relevantes en las que aparece la criada, para matizar algunas de las conclusiones a las que habían llegado las referidas estudiosas. En su análisis de la escena del comportamiento poco decoroso de Lucrecia, el «impetuoso abrazo con el que Lucrecia recibe a Calisto» (1997: 36), Beltrán apunta una breve lista de situaciones extrañas en las que la criada participa, como el que diga que reconoce a Calisto por la voz cuando supuestamente no lo ha visto antes. A continuación resume lo dicho por Eaton, que infiere que Lucrecia había sido cortejada por Calisto o Tristán, o que Calisto ya había rondado por el huerto de Melibea en otras ocasiones. Concluye Beltrán que «los abrazos de Lucrecia no se justifican sencillamente» por la proximidad entre amos y criados en esta época que aducía Lida de Malkiel (1962: 645), hipótesis ésta que resta importancia a la acción de la criada y la mantiene en su papel de secundaria, donde correría, y ha corrido, el riesgo "de pasar desapercibida al lector, como suele ocurrir con los secundarios, que además reciben rara u oblicuamente las miradas de los críticos» (Beltrán, 1997: 16). Quizá sea prueba de ello el que en su edición de la Tragicomedia, en la lista de criados, Russell haya posicionado a Lucrecia detrás de Sosia y Tristán, y no como creo que cabría esperar detrás de Sempronio y Pármeno, aunque sólo fuera por lo que se refiere a tiempo de palabra o presencia en los diversos autos. Desde luego, la presencia de Lucrecia en la Tragicomedia se ve notablemente ampliada al compartir las nuevas escenas que incluye el autor en ese alargamiento del deleite de los amantes ${ }^{2}$, y es precisamente en una de esas ampliaciones cuando Lucrecia protagoniza el episodio del que quiero hablar aquí.

Lo cierto es que Lucrecia sale en escasas ocasiones de su papel de criada algo deslenguada pero finalmente discreta, o doblemente discreta. Primero por ser partícipe de los amores de su ama, siendo el único testigo ocular - en una ocasión por invitación expresa de Calisto- de los encuentros nocturnos de los amantes; y luego por el hecho de conocer sobradamente la calaña de Celestina y el peligro que conlleva para el honor cualquier relación con la vieja alcahueta. Esta discreción, esta manera de fundirse con el paisaje, quizá sea su rasgo característico, y el que explique también la relativa falta de interés por parte de los especialistas de la que

2.- Mota (2000: clxxxiii) afirma que "La criada y doncella de compañía de Melibea es un personaje claramente reconsiderado entre la Comedia y la Tragicomedia. En la primera versión Lucrecia es poco más que una sirviente fiel, que observa hacer a sus señores». 
se lamentan Eaton y Beltrán. Cuando Lucrecia se aferra a Calisto, sorprende que haya pasado de un segundo plano a otro mucho más visible y que haya robado el protagonismo a los amantes, aunque sólo sea por unos momentos.

Cualquiera que se haya interesado por la onomástica de La Celestina, habrá reparado en el nombre de alcurnia que ostenta la criada. Para Kurt y Theo Reichenberger el nombre es indudablemente una alusión a la célebre matrona romana, parangón de la virtud, mujer luego deshonrada y que compra su honor a cambio de su vida ${ }^{3}$. Llegan ambos estudiosos a la conclusión de que "Galardonar la fiel y honesta criada con el nombre de Lucrecia nos revela el carácter noble del autor» (Reichenberger, 2001: 236). Esta idea concuerda perfectamente con el juicio que ofrece Beltrán cuando observa que «Lucrecia se nos dibuja al inicio como la vigilante de una moral estrecha, la moral dominante - y falsa- de los adultos» (Beltrán, 1997: 34); concuerda también con algunas palabras del texto que, como la aparentemente discreta criada, podrían pasar desapercibidas, cuando se está buscando en la obra otras cosas, y otros personajes de mayor enjundia. En los versos acrósticos de la Comedia la última estrofa alude in extenso a la Pasión de Cristo, pero esta estrofa piadosa se ve reemplazada en la Tragicomedia por otra de orden moral, cuyos primeros versos rezan: "O damas, matronas, mancebos, casados / notad bien la vida que aquestos hizieron; / tened por espejo su fin qual huvieron, / a otro que amores dad vuestros cuydados» (p. 193, n. 27)4. Creo que a ningún estudiante de la época, ni a ningún lector erudito se le habría escapado la posible alusión a la Lucrecia romana que parece encerrar la palabra «matronas», además tan estrechamente vinculada aquí a ese «fin» que comparten muchos de los personajes de la Tragicomedia, y sobre todo Melibea, única en suicidarse como la matrona romana. Desde luego que las correspondencias entre la matrona romana y la criada son de lo más escurridizas. Comparten nombre, en efecto, pero la Lucrecia de Rojas no obra con virtud parangónica, y es Melibea quien, como cualquier dama que se respete, hace alarde de su propia virtuosa conducta. La Lucrecia de Rojas no se suicida, pero está presente en el momento en que se suicida su ama; y de este modo se encuentran asociados el nombre de la matrona y su trágico fin, un trágico fin que Rojas prevé para las vidas desordenadas y locas de sus personajes y quienes los imiten. Quizá, como veremos, Lucrecia no hace sino imitar (brevemente) el mal ejemplo de sus amos. Los fallos de carácter que los citados críticos han visto en la criada, capaz de introducir en la casa de sus señores a una notoria alcahueta y de

3.- Kurt y Theo Reichenberger (2001: 225-250). Véase también Kurt Reichenberger y Tilbert Stegman (2001: 251-259), donde a pesar de establecer vínculos entre el nombre de Calisto y uno de los papas Borgia, Calisto III, no extienden la comparación a Lucrecia.

4.- Las citas son de la edición de Russell (1991). 
aceptar unos sobornos baratos, desdoran su imagen de virtud, y cualquier relación con la matrona romana se ha de ver en términos de punto de comparación y contraste. Más apropiado sería la relación entre el nombre de la criada y Lucrecia Borja, mujer menos conocida por su castidad. Los Reichenberger (2001: 249) evocan casi por casualidad la asociación, pero sin entrar demasiado en detalles.

Las páginas que siguen no tienen desde luego como objetivo rescatar a Lucrecia de su papel de personaje secundario para intentar hacer de ella lo que no es, ni pretendo yo aquí repasar su trayectoria a lo largo y ancho de la obra. Existen ya trabajos sobre esta cuestión a los cuales me he referido. El propósito de esta comunicación es el de estudiar el episodio de ostentación amorosa al que he aludido e intentar ofrecer una solución plausible para explicar el extraño comportamiento de la criada.

Hace cierto tiempo ya, Alan Deyermond escribió un artículo ${ }^{5}$, ampliamente comentado por otros estudiosos ${ }^{6}$, en el que ponía de manifiesto una serie de concatenaciones o equivalencias simbólicas que tenían como denominador común la magia demoníaca de la que, según el crítico, usa Celestina. Resumiendo: en su ceremonia de convocación de los espíritus infernales el demonio entra en el hilado que Celestina desea vender en casa de Melibea, siendo la venta de éste el pretexto para acudir a la puerta de Pleberio sin levantar sospechas. El demonio encerrado en el círculo mágico del hilado afloja la resistencia de Melibea al discurso de Celestina $y$, al entregar la joven su cordón para curar el falso dolor de muelas de Calisto ${ }^{7}$, el demonio, según Deyermond, pasa a esta nueva prenda. Cuando la prenda llega a manos de Calisto, el comportamiento del joven también experimenta una reacción que los propios personajes tildan de extraña ${ }^{8}$. Deyermond reconoce que la próxima etapa de transmisión demoniaca no es tan clara ni inmediata como en el caso anterior, "the correspondence is not perfect» (1977: 9), aunque ofrece una convincente respuesta a esta aparente traba. Pasa cierto tiempo antes de que Calisto dé una cadenilla de oro a la alcahueta a modo de recompensa. La equivalencia que ve el crítico no sólo reside en la forma de la cadena (circular, hay que suponer), que recuerda tanto la del hilado como la del cordón, sino también en el

\section{5.- «Hilado-cordón-cadena: Symbolic Equivalence in La Celestina» (1977).}

6.- Botta (1994: 36-67) habla de "'continuaciones' [...] mayormente publicadas en la revista norteamericana Celestinesca» de las ideas desarrolladas por Deyermond. El artículo de Botta da debida cuenta de la bibliografía al respecto. La estudiosa sigue en gran medida las conclusiones de Deyermond en las pp. 55-57.

7.- Sobre el dolor de muelas de Calisto, ver el trabajo reciente de Beresford (2000: 39-57). Otro artículo reciente relacionado, de López-Ríos, y que a la hora de escribir estas líneas no he podido consultar, es «La oración a Santa Apolonia de La Celestina a la luz del folklore médicoreligioso", en Ruano de la Haza y Maestro (2008: 59-76).

8.- Según Botta (1994: 55-56) «empieza a desvariar y a portarse de una forma del todo anormal». 
hecho de que este nuevo círculo mágico en el que se encuentra el demonio obra efectos trastornadores idénticos en el portador, o portadora. Celestina pasa de ser mujer sabia y astuta a vieja dominada por la avaricia, e inconsciente de la creciente ira de los dos igualmente avariciosos criados, Sempronio y Pármeno.

El estudioso británico menciona de paso que hay otro momento en el que uno de los componentes de la secuencia simbólica vuelve a aparecer. En el auto IX, Lucrecia llega a casa de Celestina para reclamar el cordón de Melibea. Dice la criada: «Mi venida, señora, es lo que tú sabrás: pedirte el ceñidero. Y demás desto te ruega mi señora sea de ti visitada, y muy presto, porque se siente muy fatigada de desmayos y dolor del coraçón» (cursiva mía, p. 422).

El breve intercambio que sigue merece ser reproducido enteramente por su interés para las observaciones que quiero desarrollar a continuación:

Cel.- Hija, destos dolorcillos tales, más es el ruydo que las nueces. Maravillada estoy sentirse del coraçón muger tan moza.

Luc.- ¡Assy te arrastren traydora! ¡Tú no sabes que és! Haze la vieja falsa sus hechizos y vase; después házese de nuevas!

Cel.- ¿Qué dices, hija?

Luc.- Madre, que vamos presto y me des el cordón.

Cel.- Vamos que yo le llevo (pp. 422-423).

Estas palabras reúnen con gran economía la idea de la hechicería («Hace la falsa vieja sus hechizos»), la identificación de la víctima del maleficio, Melibea ("muger tan moza»), y uno de los símbolos de la magia en la obra, el cordón. En su comentario al respecto, Deyermond apunta que "Celestina [...] is apparently returning it [el cordón] to Melibea", concediendo que Rojas no nos muestra el momento de la entrega. Quisiera detenerme un poco más en esta escena antes de pasar a la etapa final de este trabajo.

El intercambio entre alcahueta y criada empieza con una afable bienvenida antes de que Lucrecia anuncie el motivo de su visita. A partir de ese momento Celestina adopta su tono condescendiente, mofándose de la gravedad de la supuesta dolencia de Melibea. Es una actitud que provoca la ira de Lucrecia en una reacción comparable a las que ofrecen en su momento Sempronio y Pármeno, aunque la discreta Lucrecia lo diga sotto voce y sin consecuencias para la vieja. Lo relevante en un autor como Rojas es que, tomando en cuenta que la entrega del cordón no se presencia

9.- Muchos son los críticos que relacionan este dolor de corazón y las serpientes que dice tener Melibea en el cuerpo con la presencia demoniaca en las artes de la alcahueta Celestina. Remito de nuevo a Botta (1994). Son de lectura obligada, entre otros muchos, Russell y la monografía de Severin (1995). 
en las escenas siguientes y habiendo hecho alusión al retorno del mismo en las palabras explicatorias de Lucrecia, vuelva a mencionarlo al final del intercambio entre las dos mujeres. En esta nueva mención de Rojas vemos acaso el deseo de Lucrecia de ser ella quien devuelva la prenda a Melibea (esperando recibir su propio premio) pero sobre todo la insistencia de Celestina para llevarlo ella misma y no cederlo a terceros, acción que de nuevo, y creo que de manera todavía más clara, prefigura la escena en que Celestina se aferra a la cadena en lugar de compartirla con sus enfurecidos cómplices. Viene al caso recordar que cuando Celestina se dirige a casa de Calisto con el cordón y se encuentra con Sempronio se niega rotundamente a revelar lo que trae, lo que origina un primer momento de tensión entre el criado y la alcahueta - en torno a la "partezilla» (p. 330) que Celestina pretende ofrecer a Sempronio como recompensa. A la luz de las afirmaciones de Deyermond, el episodio de Lucrecia y Celestina con la presencia de la palabra "hechizos» y con el motivo del cordón-círculo mágico, junto al parecido estructural con el de Sempronio y Celestina, dan qué pensar. La mención del cordón dos veces en un intercambio relativamente banal, también.

En los casos evocados por Deyermond, los personajes que de alguna manera tienen relación o contacto con los objetos mágicos «hilado-cordón-cadena» se ven presos de comportamientos extraños; quiero pues sugerir ahora que Lucrecia, al ir a buscar el cordón a casa de Celestina, al estar en contacto físico (o meramente por su proximidad) con el cordón de su ama, una vez infiltrado éste por la presencia demoniaca, experimenta igualmente un cambio de comportamiento ${ }^{10}$. Se podría fácilmente objetar aquí lo que el propio Deyermond ofrece como posible fallo en su razonamiento, la falta de inmediatez entre el acercamiento o contacto con el objeto y el momento en el que tiene lugar el comportamiento inhabitual $^{11}$. Se podría objetar además que, si adoptamos la hipótesis del mis-

10.- Hace unos años Márquez Villanueva (1993: 183) parecía inferir la presencia de una influencia extraña que explicase el comportamiento de Lucrecia: «El oficio de la vieja [Celestina], consistente en llevar su corrupción a todos los rincones, tiene un perfecto homólogo o correlato semiológico en el famoso 'hilado' que termina por introducir en la propia casa de Melibea y donde ésta (y hasta un poco también su criada Lucrecia) arderá pronto de incontenible lujuria». Agradezco a Amaia Arizaleta el haberme señalado este dato.

11.- Fray Eusebio González de Torres recoge un caso, entre los muchos que se podrían citar, que guarda cierto parecido (comportamiento extraño, influencia demoniaca, objeto endemoniado) con lo que ocurre en Celestina. El caso se da en tiempos de Enrique iv (modernizo la ortografía): «Leonora González, dama de la Reyna de España, doña Juana, mujer de Enrique Iv, llegó a la capilla de S. Diego, en cumplimiento de un voto que hizo al Santo, por aver éste librádola de unas molestas calenturas luego que hizo el voto. Pero apenas entró en la capilla, cuando encendida de repente la calentura la puso en gravísima congoja, despertando el recelo de que fuese tan impensado accidente justo castigo de algún pecado oculto. Con este cuidado, examinada con gran exacción su conciencia y viendo que nada hallaba que de la vida presente la acusase, entró en nuevo recelo de que en un bolsillo de reliquias que traía consigo hubiese algún hechizo, o cosa supersticiosa. Para salir de esta duda, entregado el 
mo estudioso, el demonio deja el cordón para entrar en la cadena de oro, con lo cual ya no está en el cordón, pero ni Rojas dice que pasa del hilado al cordón, ni que una vez dentro se quede allí: seguimos con las conjeturas y la mía es una más. Las reacciones de Melibea y de Calisto ante los objetos son inmediatas o casi inmediatas, la reacción de Celestina más distante en el tiempo, la de Lucrecia, algo más distante aún. Si aceptamos la idea de influencia demoniaca tenemos pues finalmente lo que podríamos llamar dos pautas: un diablo que obra con rapidez en determinados momentos y con más pausa en otros. El extraño comportamiento de la criada se podría entonces explicar por la fuerza del hechizo, que se transfiere a o permanece en los distintos objetos circulares manejados por las respectivas víctimas.

La escena protagonizada por Lucrecia en la que se abraza a Calisto se desarrolla de la siguiente manera. Al estar Melibea hablando con Calisto, Lucrecia lo abraza, según nos revela su ama:

Lucrecia, ¿qué sientes amiga? ¿Tórnaste loca de plazer? Déxamele, no me le despedaces, no le trabajes sus miembros con tus pesados abraços. Déxame gozar lo que es mío; no me ocupes mi plazer (p. 571).

A lo que Calisto responde : «Pues señora y gloria mía [...]».

El texto que acabo de citar, así aislado, poco parece tener de inspiración mágica o demoniaca, poco parece revelar salvo la impetuosa actitud de Lucrecia. Pero guarda un notable parecido con otro episodio de la obra en el que se encuentra un comportamiento casi idéntico de pasión mal controlada: el que nos muestra a Calisto en el momento en el que recibe el cordón de manos de Celestina. Dejando aparte las similitudes exclamatorias que preceden ambos episodios, digna de interés es la reacción de Celestina frente al exagerado comportamiento de Calisto, dice:

Cessa ya, señor, esse desvanear; que a mí tienes cansada de escucharte y al cordón roto de tratarlo (p. 351).

Vemos en esta réplica el deseo de Celestina de que cese el espectáculo grotesco $^{12}$. La vieja insta a Calisto que deje de comportarse así, de igual

bolsillo a un religioso docto del convento, que le examinó con cuidado, halló en él un papel lleno de caracteres, unos incógnitos, y otros arábigos, en que se expresaban muchos nombres de espíritus infernales. No fue menester más examen para darle a las llamas y ejecutada esta diligencia, la dama, que con invencible ignorancia y buena fe había recibido el papel como preservativo de hechizos, quedó libre de la calentura y del engaño y de los malos efectos que por él la pudieron sobrevenir", en Chronica seráphica [sexta parte], dedicada a Nuestro Reverendisimo P. Fray Juan de Soto, Comisario General de toda la Orden de N. P. S. Francisco en esta familia Cismontana y de las Indias \& C., Madrid, Viuda de Juan García Infanzón, 1725, la cita aparece en los fols. Ll6r ${ }^{\circ} b-L 16 v^{\circ}$ a.

12.- Sobre este episodio ver Gerli (2003: 191-209; en part., 194 y ss). 
manera que hará Melibea con Lucrecia. Pero lo más interesante está por llegar. Calisto responde:

¡O mezquino de mí! Que asaz bien me fuera del cielo otorgado que de mis braços fueras fecho y texido, no de seda como eres, porque ellos gozaran cada día de rodear y ceñir con devida reverencia aquellos miembros que tú, sin sentir ni gozar de la gloria, siempre tienes abraçados. ¡O qué secretos havrás visto de aquella excelente ymagen! (cursiva mía, p. 351) ${ }^{13}$.

Un cotejo rápido revela los siguientes parecidos:

\begin{tabular}{|c|c|c|}
\hline $\begin{array}{c}\text { Palabras de Melibea, } \\
\text { auto XIX }\end{array}$ & $\begin{array}{c}\text { Palabras de Calisto, } \\
\text { auto VI }\end{array}$ & $\begin{array}{c}\text { Palabras de Celestina, } \\
\text { auto VI }\end{array}$ \\
\hline despedaces & - & roto \\
\hline loca & - & desvaneo \\
\hline miembros & miembros & - \\
\hline abraços & abraçados & \\
\hline trabajes & - & tratarlo[?] \\
\hline gozar & $\begin{array}{l}\text { gozar, gozarán } \\
\text { gloria (que se emplea } \\
\text { igualmente en la escena } \\
\text { de Lucrecia, auto XIX) }\end{array}$ & - \\
\hline
\end{tabular}

Como se puede observar en la comparación de estos cortos fragmentos de texto, tanto las situaciones como los vocablos que escogió Rojas guardan una relación más que llamativa entre sí. Como poco, estamos ante un caso de intertextualidad nada inusual en la obra que nos ocupa, los ecos y las anticipaciones son numerosas en La Celestina, aunque la concentración de puntos comparables aquí sobrepasan sin duda la media. Puede que todo sea mera coincidencia, la de un Rojas que añade en este decimonono auto unos elementos más para rebajar a Calisto y también a Melibea, ya que después de todo trata a Lucrecia de "amiga» ${ }^{14}$. Eaton,

13.- El texto citado aquí y las palabras de Celestina pasan de la Comedia a la Tragicomedia sin cambios significativos. Para el texto de la Comedia y las leves variantes ver la edición de Rank (1978).

14.- Algunas nociones sobre el tratamiento empleado por los personajes se encuentran en el ya citado estudio de Mota (2000: clviii y ss.), y en el «Estudio preliminar» de Rico (2000: xlii y ss., en part.). Viene al caso recordar aquí las palabras de Areúsa cuando describe la vida de las criadas: «Nunca oyen su nombre propio de la boca dellas [las amas], sino i'puta acá ! i'puta acullá'» (p. 416). Melibea, sin embargo, suele llamarla por el nombre en la mayoría de las ocasiones en las que se refiere a ella. Pero tras la segunda visita de Celestina el trato es aún más familiar y notablemente parecido al que emplea para designar a la vieja. "Pues ve, mi señora, mi leal amiga», dice la joven a Celestina y a la criada en su siguiente réplica: "Amiga, Lucrecia, mi leal criada» (lo que aparece en cursiva es añadido de la Tragicomedia) (p. 439). El paralelismo entre ambas frases salta a la vista. El que llame «amiga» a la criada en el episodio del abrazo no puede sino reflejar, al menos en parte, el descenso moral de la joven dama. Ver Beltrán (1997), 
al hablar de condición de la criada y de la presencia de Lucrecia en los encuentros amorosos de su ama, avanza lo siguiente:

In La Celestina, the idea (or myth) of the loyal servant is exposed and satirized along with the sentimental concepts of nobility and virginity expressed by the word donzella. The traditions behind the words donzella and encerramiento are cheapened in being applied to Lucrecia (and in Celestina's hovel) just as Lucrecia degrades Melibea's love affair by remaining as a witness to it, giving a cynical, play by play account (Eaton [1973: 222]).

Si creemos el texto, a Calisto apenas si le afectan los pesados abrazos de la criada, pues no se digna a comentar lo sucedido sino que se dirige a Melibea, en esa escena que pone en evidencia la poca galantería de Calisto, que antes de espetar su crudísima frase, «Señora, el que quiere comer ave primero quita las plumas», ha procedido a destrozar la ropa a Melibea. "¿Qué provecho te trae dañar mis vestiduras?» (p. 371), dice una exasperada Melibea al final de una larga queja, un final que podría fácilmente recordar al lector el episodio del cordón maltratado, de seda como "el hábito de encima» de Melibea, o bien las palabras de la prostituta Areúsa cuando Pármeno actúa de manera semejante a su amo, en otro caso revelador de la constante intertextualidad presente en la obra. Tras una primera amonestación ("No sera él tan descortés que entre en lo vedado sin licencia», p. 379), Areúsa, sorprendida, colérica o quizá fi giendo ambas cosas, dice:

¡Ay señor mío, no me trates de tal manera! ¡Ten mesura, por cortesía, mira las canas de aquella vieja honrrada, que están presentes! ¡Quítate allá, que no soy de aquellas que piensas! No soy de las que públicamente están a vender sus cuerpos por dinero. jAssí goze de mí, de casa me salga si, fasta que Celestina, mi tía, sea yda, a mi ropa tocas! (pp. 379-380).

Encontramos aquí los mismos ingredientes básicos, un amante impaciente, una amada nada satisfecha del trato recibido y una observadora. En esta escena, quien observa es Celestina; en aquélla, Lucrecia. Si hemos de creer lo que dice la primera y lo que se dice de la segunda, ambas se encuentran alejadas del placer carnal, una por vieja, la otra por criada ${ }^{15}$.

para quien, siguiendo la tesis de Eaton, «la alabanza de Melibea hacia la fidelidad de la criada es prueba no de la virtud objetiva de Lucrecia, sino de la equivocada valoración que Melibea hace de los seres que la rodean» (p. 34).

15.- Esta segunda queja de Areúsa fue añadida en la Tragicomedia. Russell (1991: 379-380, n. 97a), observa lo siguiente: «Empieza una adición cuyo fin principal es hacer más explícitos, por medio de la descripción dialogada, los retozos sexuales de Pármeno y Areúsa, a la vez 
Que la criada Lucrecia, como Melibea, sea víctima de un maleficio, aunque sea ya el último coletazo de un hechizo sobre el cual se ha perdido el control, o que se trate como han señalado algunos críticos de un arrebato causado por las canciones y las ardorosas palabras de los amantes ${ }^{16}$, el episodio tiene el mérito de darle a la discreta Lucrecia su momento de pasión efímera en un mundo en el que se ha paseado hasta ese instante como observadora ${ }^{17}$. Su irrupción en el encuentro entre Calisto y Melibea corta momentáneamente el acercamiento de los jóvenes. Presenciamos las quejas de Melibea que quiere gozar lo suyo, su "plazer», un placer que se convierte enseguida en un triste eco, amplificado, de la grotesca escena de fetichismo, y en un triste eco de las palabras que ella misma dirigió a su criada. No son los miembros de Calisto los que se ven trabajados por pesados abrazos, sino los de Melibea. No es Calisto el despedazado, aunque poco le queda ya de vida y de entereza corporal, sino Melibea o sus ropas, en una de las muchas escenas peculiares de ésta tan ambigua obra. Lucrecia, como en otras escenas, se convierte de nuevo en personaje secundario y transparente, fundiéndose con ese mundo de las sombras y de los apartes y el hablar entre dientes con el consiguiente dolor de muelas ${ }^{18}$.

que atribuye a la alcahueta un vivo deseo de presenciar, como patrocinadora, la cópula de la pareja». ¿Y si el fin principal fuera el de establecer un punto de comparación entre la torpeza de Pármeno y la inelegante acción de su amo?

16.- Así por lo menos lee la escena Russell (571, n. 42): «La criada inflamada por las cantigas amorosas y por las palabras de su ama, se aprovecha de la ocasión para abrazar ella misma con fogosidad a Calisto». Parecida conclusión saca Severin (1988: 323, n. 9): «Lucrecia, como anteriormente Sempronio, se ve tambien influida por la sensualidad de la escena».Ver también Gerli (2003: 205-206).

17.- Gerli (2003: 206) dice «Más que la encarnación de un deseo desbordante, sin embargo, Lucrecia es el personaje de mayor intensidad voyeurística en toda Celestina». Puede que el crítico tenga razón, en particular en la segunda parte de su aserto, sin embargo, en el episodio del abrazo sí representa a ese deseo desbordante e incontrolado que caracteriza a otros personajes.

18.- O será mera coincidencia que Calisto sufre un supuesto dolor de muelas y Lucrecia aquí aluda, aunque de manera oblicua, a sus dientes: «Que me esté yo deshaciendo de dentera, y ella esquivándose porque la rueguen!» (p. 572). 


\section{Bibliografía citada}

Beltrán, Rafael (1997), "Eliseu (Tirant lo Blanc) ante el espejo de Lucrecia (La Celestina): retrato de la doncella como cómplice fiel del amor secreto", en Cinco siglos de Celestina: Aportaciones interpretativas, eds. Rafael Beltrán y José Luis Canet, Col.lecció Oberta, València, Universitat de València, pp. 15-41.

Beresford, Andrew M. (2000), “Una oración, señora, que le dixeron que sabías, de Sancta Polonia para el dolor de muelas': Celestina and the Legend of St Apollonia», en Context, Meaning and Reception of Celestina. A Fifteenth Century Symposium, eds. Ian Michael y David G. Pattison, Carfax, Taylor \& Francis/University of Glasgow, pp. 39-57.

BotTA, Patrizia (1994), «La magia en La Celestina», Dicenda. Cuadernos de Filología Hispánica, 12, pp. 36-67.

Deyermond, Alan (1977), «Hilado-cordón-cadena: Symbolic Equivalence in La Celestina», Celestinesca, 1.1, pp. 6-12.

EAton, Katherine (1973), "The Character of Lucrecia in La Celestina», Annali dell'Istituto Orientali di Napoli-Sezione Romanza, 15, pp. 213-225.

GerLI, E. Michael (2003), «El placer de la mirada: voyeurismo, fetichismo y la movilización del deseo en Celestina», en El mundo social y cultural de La Celestina, eds. Ignacio Arellano \& Jesús M. Usunáriz, MadridFrankfurt Main, Iberoamericana-Vervuet, pp. 191-209.

GonzÁlez de Torres, Eusebio (1725), Chronica seráphica [sexta parte], dedicada a Nuestro Reverendísimo P. Fray Juan de Soto, Comisario General de toda la Orden de N. P. S. Francisco en esta familia Cismontana y de las Indias \& C., Madrid, Viuda de Juan García Infanzón.

Lida de Malkiel, María Rosa (1962), La originalidad artística de "La Celestina», Buenos Aires, Eudeba.

López-Ríos, Santiago (2008), "La oración a Santa Apolonia de La Celestina a la luz del folklore médico-religioso", en La dramaturgia de 'La Celestina', eds. José María Ruano de la Haza y Jesús G. Maestro, Vigo, Editorial Academia del Hispanismo, pp. 59-76.

Márouez Villanueva (1993), Francisco, Orígenes y sociología del tema celestinesco, Barcelona, Antropos.

MotA, Carlos (2000), "Articulación y contenido. Los personajes», en $\mathrm{La}$ Celestina. Tragicomedia de Calisto y Melibea, ed. y estudio de Francisco J. Lobera, Guillermo Serés et al., Barcelona, Crítica, pp. cxxv-ccviii.

Rank, Jerry R. (1978), Fernando de Rojas, Comedia de Calisto y Melibea, ed. Chapel Hill, Estudios de Hispanófila. 
ReICHENBERGER, Kurt y Theo (2001), «Fernando de Rojas como comentarista político: acerca de la elección de los nombres para los personajes en La Celestina», en Tras los pasos de "La Celestina", eds. Patrizia Botta, Fernando Cantalapiedra, Kurt Reichenberger y Joseph Snow, Kassel, Reichenberger, pp. 225-250.

-y Tilbert SteGman (2001), «La denominació dels personatges de La Celestina en el seu context històric", en Tras los pasos de "La Celestina", eds. Patrizia Botta, Fernando Cantalapiedra, Kurt Reichenberger y Joseph Snow, Kassel, Reichenberger, pp. 251-259.

Rico, Francisco (2000), "Estudio preliminar», en La Celestina. Tragicomedia de Calisto y Melibea, ed. y estudio de Francisco J. Lobera, Guillermo Serés et al., Barcelona, Crítica, pp. xiii-xlvii.

Russell, Peter E. (1991), Comedia o Tragicomedia de Calisto y Melibea, Madrid, Castalia.

Severin, Dorothy S. (1988), La Celestina, Madrid, Cátedra.

- (1995), Witchcraft in 'Celestina', PMHRS, 1, London, Queen Mary and Westfield College. 


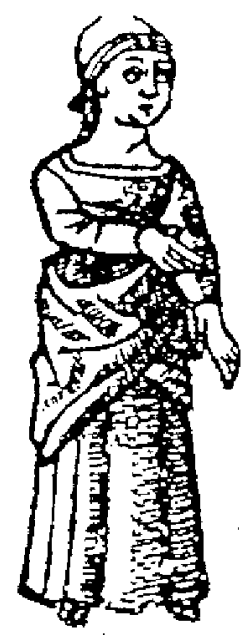


GonZÁlez FernándEZ, Luis, "Algunas consideraciones sobre la criada Lucrecia», Celestinesca, 32 (2008), pp. 151-163.

\section{RESUMEN}

Esta comunicación tiene como objetivo ofrecer una descripción sucinta de la criada de Melibea, Lucrecia, a la vez que intentará hacer un breve estado de la cuestión sobre el personaje. Se tratará luego de examinar de nuevo algunas de las conclusiones a las que llegó Alan Deyermond acerca del papel de la magia en la obra. Siguiendo un estudio intertextual de La Celestina intento relacionar el personaje de Lucrecia con la concatenación de episodios estudiados por Deyermond para, por fin, llegar a la conclusión de que ella también es víctima de la influencia demoniaca desatada por Celestina. Las páginas finales de este artículo ofrecen algunas observaciones acerca del papel de la criada en las últimas escenas de la obra.

PALABRAS CLAVE: Lucrecia, magia, intertextualidad.

\section{ABSTRACT}

This article seeks to offer a succinct description of Melibea's maidservant, Lucrecia, as well as detailing a brief state of the question. Some of the conclusions concerning magic arrived at by Alan Deyermond will also be examined in order to suggest that Lucrecia is also a victim of the demonic influence unleashed by Celestina. The final pages of this article offer a number of observations concerned with the maid's role in the closing scenes of the work.

KEY WORDS: Lucrecia, magic, intertextuality.

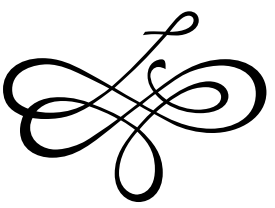

